
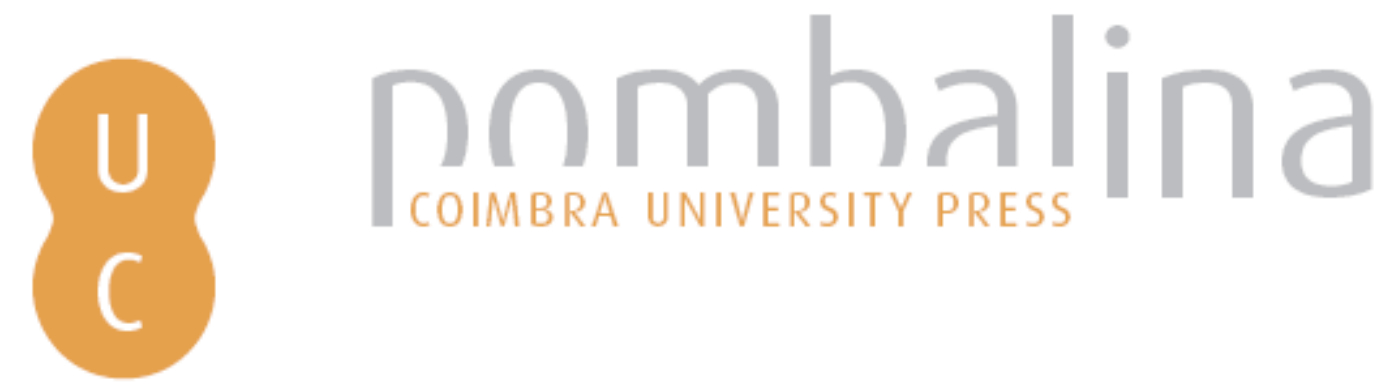

\title{
A construção de saberes matemáticos na educação de jovens e adultos: um estudo a partir da concepção pedagógica freireana
}

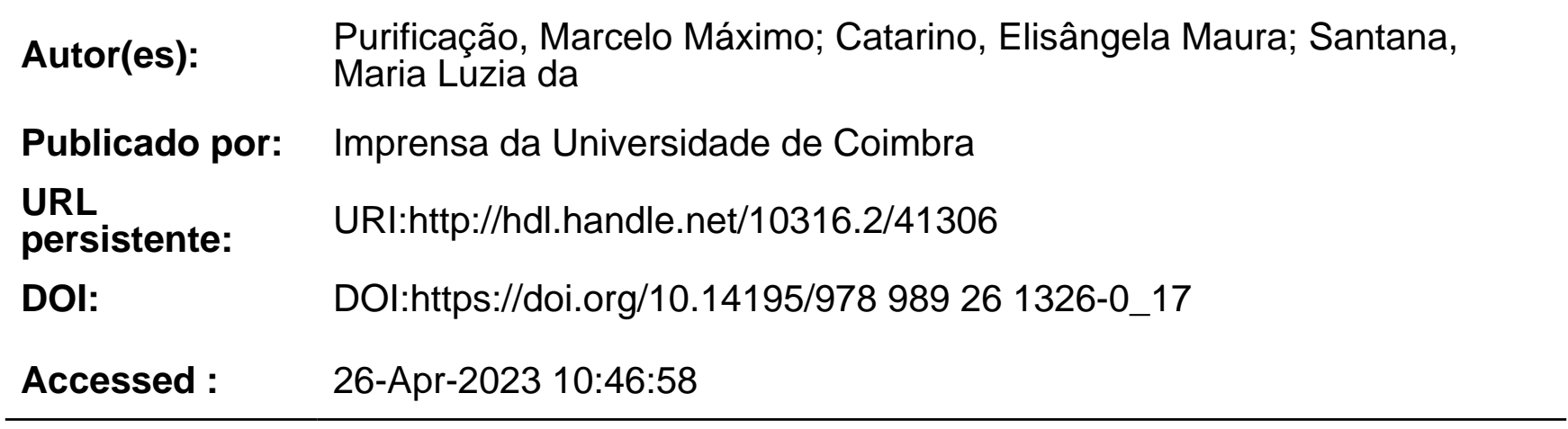

A navegação consulta e descarregamento dos títulos inseridos nas Bibliotecas Digitais UC Digitalis, UC Pombalina e UC Impactum, pressupõem a aceitação plena e sem reservas dos Termos e Condições de Uso destas Bibliotecas Digitais, disponíveis em https://digitalis.uc.pt/pt-pt/termos.

Conforme exposto nos referidos Termos e Condições de Uso, o descarregamento de títulos de acesso restrito requer uma licença válida de autorização devendo o utilizador aceder ao(s) documento(s) a partir de um endereço de IP da instituição detentora da supramencionada licença.

Ao utilizador é apenas permitido o descarregamento para uso pessoal, pelo que o emprego do(s) título(s) descarregado(s) para outro fim, designadamente comercial, carece de autorização do respetivo autor ou editor da obra.

Na medida em que todas as obras da UC Digitalis se encontram protegidas pelo Código do Direito de Autor e Direitos Conexos e demais legislação aplicável, toda a cópia, parcial ou total, deste documento, nos casos em que é legalmente admitida, deverá conter ou fazer-se acompanhar por este aviso.

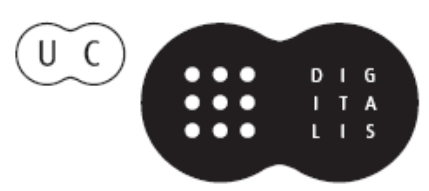




\title{
17. A CONSTRUÇÃO DE SABERES MATEMÁTICOS NA EDUCAÇÃO DE JOVENS E ADULTOS : \\ UM ESTUDO A PARTIR DA CONCEPÇÃO PEDA GÓ G I CA FREIREANA
}

\author{
Marcelo Máximo Purificação ${ }^{74}$ \\ Elisângela Maura Catarino 75 \\ Maria Luzia da Santana 76
}

\begin{abstract}
Resumo
O espaço escolar pode ser visto como um lugar onde as novas competências devem ser adquiridas, reconhecidas e desenvolvidas. O presente trabalho é um recorte da ideia central que integra o Projeto Matematicando, realizado pela primeira vez em 2003 com jovens e adultos do CEPLOS/SEDUC/GO, depois desenvolvido em programas de formação de professores nos cursos de pedagogia e matemática em Brasília e Goiás (Brasil).
\end{abstract}

${ }^{74}$ Pós-doutorando na Universidade de Coimbra - FPCE, doutor em Ciências Sociais e da Religião pela PUC-Goiás, mestre em Ciências Educacionais (UEP) e mestre em Educação Comunitária pela UFRGS/EST. Professor Adjunto DII na UNIFIMES, Goiás Brasil e Professor P-IV na SEDUCE/GO. E-mail: maximo@fpce.uc.pt

75 Doutora em Ciências Sociais e da Religião pela PUC-Goiás, mestra em Educação Comunitária pela UFRGS/EST, professora efetiva da SEDUCE-GO e Substituta na UNIFIMES.E-mail: maura@fimes.edu.br

${ }^{76}$ Doutoranda e Mestra em Psicologia pela UCB e Professora Adjunta na UNIFIMES. E-mail: marialuzia@fimes.edu.br 
Nesse contexto, o objetivo era propor aos alunos ingressantes no ensino superior, um nivelamento nos conteúdos pedagógicos e matemáticos, e com isso, o projeto foi executado dentro de alguns programas de nivelamentos, em instituições diferentes. Em 2014/2, o projeto foi desenvolvido junto a Pró-reitora de Extensão da Universidade Estadual de Goiás - UEG, no Campus de Mineiros, e hoje (2015) na UNIFIMES, voltando a ser executado com o nome inicial - matematicando. Nessa nova fase de execução, o projeto tem como prioridade, dissertar sobre algumas motivações (histórias de vidas - prática e teóricas) que conduziram os alunos até a Universidade. O ponto de partida para essa nova etapa do projeto é o estudo e a análise detalhada de práxis pedagógicas de sucessos desenvolvidas por alguns professores, aliando a essas, a construção sociocultural do povo brasileiro, a partir do viés crítico e reflexivo, tendo como aparato as concepções freireanas. No universo acadêmico, constituído por jovens e adultos, a boa comunicação entre professores e alunos, pode ser um instrumento eficaz na construção do pensamento crítico e reflexivo que reforça a motivação e a aprendizagem, pois, as relações dialogais motivam o alunado e promovem o seu desenvolvimento no processo. Isto dito fica explícito o objetivo do presente texto, que é analisar os conceitos de educação popular e pedagogia crítica, propagados por Paulo Freire, pontuando os possíveis liames entre a educação popular, educação crítica e emancipatória para construção do conhecimento matemático dos alunos calouros no ensino superior.

\section{Abstract}

School spaces can be conceived as places where new skills may be developed. This paper is one of the products of the Project "Matematicando", which was started in 2003 with youth and adults 
of CEPLOS/SEDUC/GO and, later, developed under teacher education programs in Pegagogy and Math courses in Brasília and Goiás (Brazil). The aim was to propose new students in higher education a threshold level in math and pedagogical knowledge. With this objective, the Project was developed under some threshold programs in different institutions. In 2014/2, the Project was developed through the Pro-Rectory of Public Outreach of the Universidade Estadual de Goiás (UEG - State University of Goiás), in the Mineiros Campus. Today it is developed in UNIFIMES with the initial name "matematicando". In this new phase of implementation, the Project aims to explore some motivations (life histories - practical and theoretical) that led the students to the university. The starting point of this new stage of the Project is the study and the detailed analysis of some teachers' successful pedagogical praxis, combining with them the socio-cultural construction of the Brazilian people, from the critical and reflective approach based on Freire's conceptions. In the academic world, where young people and adults come together, good communication between teachers and students can be an effective tool to build the critical and reflective thinking that reinforces motivation and learning, once dialogical relationships motivate students and promote their development in the process. Within this frame, this study analyses Paulo Freire's concepts of popular education and critical pedagogy, highlighting possible bonds between popular education and critical education for freedom and for the construction of mathematical knowledge of new students in higher education. 


\section{À Guisa de Introdução}

"A educação tem por missão despertar seres capazes de viver e comprometer-se como pessoas.” Emmanuel Mounier (1962).

Tendo como ponto de partida a produção científica desenvolvida nos últimos anos, sobretudo no que tange a formação docente na área de matemática, percebe-se uma crescente tendência de investigação sobre os processos de construção identitária desses profissionais da educação, assim como aos problemas enfrentados pelos profissionais no início de sua atuação.

Diante o exposto, pautado na prática profissional que possibilitou-me atuar como profissional da educação (professor/educador, coordenador e diretor) em instituições básicas de ensino nos níveis fundamental e médio, agregando essas vivências às experiências de sala de aula e de coordenação no ensino superior nos cursos de formação de professor de pedagogia e matemática, e na rica troca de experiência com as professoras colaboradoras desse texto, percebemos a grandiosidade e a necessidade de se conhecer tais questões, as quais vemos como relevantes para o processo ensino e aprendizagem, assim como a necessidade de se propagar os bons exemplos e as boas práticas, desenvolvidos aqui (no Brasil) e alhures (em outros países), com foco na "conscientização"77 dos atuais e futuros profissionais da educação matemática.

Fato importante para esse contexto de mudanças e construção da consciência crítica é impulsionar as ações humanas em busca

77 A consciência do mundo se dá através da relação de dialogicidade entre o homem e o mundo. Embora não pertencendo a Paulo Freire (1987, p 114), esse vocábulo está associado ao seu pensamento pedagógico e refere-se ao desenvolvimento crítico da tomada de consciência. É a superação da consciência ingênua, a partir da consciência crítica que ocorre quando o homem se apodera da realidade, transformando-a. Essa modificação da realidade é o que se chama conscientização. Somente através das práxis o homem toma consciência de si, dos outros e do mundo. 
de um mundo melhor; para isso, as ações pedagógicas devem estar atreladas às orientações curriculares e às necessidades epistêmicas e metodológicas da organização escolar, tornando-se vivas nos conteúdos de ensino, por meio da "participação"78. Como esses conceitos e categorias de pensamento estão lincados à educação popular, indubitavelmente, a contribuição de Paulo Freire (1984), precisa ser resgatada, dentro dos projetos educativos, no intuito de ancorar as mudanças curriculares levadas a efeito nas escolas. Pois como diz o próprio Freire (1987), "[...] para o educador/educando, dialógico e problematizador, o "conteúdo programático” (pp.83-84), não é uma doação ou imposição [...] mas sim, a devolução sistêmica e organizada, acrescentada do saber popular daqueles elementos que este lhe entregou de forma desestruturada. É dessa forma que o projeto busca associar os conteúdos matemáticos às experiências vividas, e isso torna a matemática mais fácil, pois é vista de forma teórica e prática, a partir das vivências dos alunos.

É com esse foco estratégico que caminha o Projeto Matematicando, quando pontua ao graduando, que no primeiro contato com a unidade escolar, seja no estágio ou no início de sua prática docente, procure analisar o perfil da unidade e de seus alunos, para melhor entender os interesses e necessidades que podem ser contemplados pelas suas ações enquanto docente. Daí a necessidade de se conhecer as memórias dos sujeitos envolvidos (alunos, parentes, lideranças comunitárias e etc.), buscando uma constituição identitária desses sujeitos e uma aproximação aos contextos de suas comunidades.

78 Para Freire (1987, p.79) é uma intenção de atuação na realidade, através das relações dialéticas, coletivas, entre o sujeito e a sua realidade cultural e histórica. Também deve ser pensada enquanto integração no sentido de poder criar, recriar, decidir, intervir, desafiando a imobilidade do estar oprimido. Sendo coletiva, a participação atinge um caráter de abertura para aprender, organizar, anunciar, construindo coletivamente dentro das identidades postas, gerando situações em que o diálogo e o conflito fortalecem o elo em analisar as inquietações e problemas vivenciados, ato essencial para pensar a mudança em benefício da igualdade entre os homens. 
Para direcionar nossa caminhada elencamos dois dos principais objetivos propostos pelo projeto, presentes em todas as suas edições, a saber: a) incentivar o desenvolvimento de habilidades básicas que possam conduzir o alunado ao aumento do hábito de: observação, criticidade, criatividade, autonomia, leitura matemática, pesquisa, (re) elaboração e sistematização de conhecimentos prévio-científicos. b) Possibilitar a troca de experiências e conhecimentos prévios entre alunos e familiares, alunos e professores, por meio do confronto sadio da comunicação dialógica e dos conhecimentos gerados por essa, oriundos das diversas áreas do saber com a matemática, expresso muitas vezes de forma expositiva, ou adquiridos por meio de pesquisa bibliográfica, de relatos de experiências, observação de dados e externá-los no ambiente escolar de forma lúdica e criativa.

$\mathrm{Na}$ linha dessas ideias, Freire apresenta a importância da comunicação para o processo ensino e aprendizagem. Combate a educação bancária por entender que essa, reflete a ausência de diálogo (comunicação) entre os atores do processo educativo, contribuindo para continuidade de um modelo de educação opressora, que não contempla o diálogo e 'troas'79 de experiências entre professor e aluno. Para Freire (1987) "nosso papel não é falar ao povo sobre nossa visão do mundo, ou tentar impô-la a ele, mas dialogar com ele, sobre a sua e a nossa" (p.87). Por isso, que o conteúdo programático (bancário) quando é imposto reforça a dominação.

\section{Desenrolar do projeto}

Até o presente momento pontuamos dentro do projeto em questão, a importância da contextualização sócio-histórica e política

79 Troas: estrondas; estrondeias; tronas; trovejas; trovoas. Estrondear: troam os foguetes e as bombardas. Soar fortemente: troam os canhões. Dicionário online de Português, disponível em http://www.dicio.com.br/troas/ acessado em 04/04/2015. 
no processo de educação de pessoas adultas. A partir dessa postura, a teoria e a prática são vistas como processos naturalmente complementares e indissociáveis. Já que "(...) o conhecimento é desenvolvido através de seu uso contínuo e situado" (Brown et al, 1989, p. 33). No entanto, quando falamos de contextualização sócio-histórica e política, remetemos mais uma vez a Freire, que chama a atenção para as questões ligadas a falsa generosidade ou assistencialismo, que é uma forma de amenizar o ato de oprimir, ou melhor: de suprimir sua aparência, de disfarçá-lo. Tal problemática está ilustrada em "Pedagogia do Oprimido" onde Freire (1987) por meio do "Sermão contra os usuários", pontua que a genuína generosidade consiste na luta contra a falsa caridade, isto é, a eliminação da relação de subserviência entre oprimido e opressor e a emersão de homens independentes, transformadores do mundo.

A partir dos objetivos supracitados anteriormente, pontuamos os principais liames que nortearam o desenrolar do Projeto Matemáticando. Que são:

a) Os conhecimentos matemáticos são construídos pelo jovem submetido a um processo de aprendizagem a partir de seus conhecimentos prévios;

b) Os símbolos e suas representatividades são espaço aberto para se trabalhar as crenças e as concepções de como ensinar e como aprender. Conhecimentos prévios versus atitudinais. $\mathrm{E}$ os elementos que possivelmente gravitam entre eles.

c) As pessoas (alunos) não são iguais, cada uma chega à escolas munidas de conhecimentos adquiridos nas suas relações sociais extramuros ao espaço escolar. Para aumentar a auto-confiança e a capacidade de aprender desses alunos, a escola precisa desenvolver atividades diversas ligadas à cultura e ao nivel do sensível como ponto de partida. No intuito de desconstruir possiveis crenças errôneas sobre o aprender 
da matemática e reforçar aquelas que significativamente servem de aparato aos novos conhecimentos.

d) As atividades interativas/lúdicas desenvolvidas em grupos são fortes aliadas do processo. Nelas, trabalham-se os níveis de aprendizagem, a partir de jogos, desafios, resolução de problemas matemáticos, quebra cabeças e outros. Objetiva-se o conhecimento matemático de forma satisfatória e divertida, com o intuito de atingir um maior nível de domínio, registro e aplicabilidades desses conhecimentos.

e) Quando se prepara o aluno/professor para o domínio, registro e aplicabilidades dos conhecimentos matemáticos, estamos empoderando-os como indivíduos para desenvolver de diferentes maneiras a transposição didática e processar intervenções e métodos diferenciados de transmissão de conhecimentos. Dessa forma, o que temos é um conhecimento matemático construído em consonância da teoria e da prática.

\section{Primeira experiência: o projeto Matematicando e o Canta Matemática}

O Projeto Matematicando nasce em 2003, no Colégio Estadual Professora Lourdes de Oliveira Sampaio em Luziânia - Goiás/Brasil. Idealizado pelos professores de matemática da unidade, na busca de melhorar o rendimento de alunos e professores da unidade escolar em questão. No primeiro momento, objetivou-se investigar as perspectivas dos alunos do Ensino Médio a respeito da matemática e sua relação com a sociedade, identificando os possíveis dilemas e tensões.

Durante todo o tempo que durou a investigação, nos deparamos inúmeras vezes envoltos nas mesmas questões: "Porque eu preciso estudar Matemática?"; "Qual é a importância da Matemática na minha vida?". Para a maioria deles, a matemática pouco influenciaria na 
sua vida futura. E o reflexo disso aparecia graficamente nos resultados das avaliações da unidade, onde a matemática se destacava como disciplina crítica.

Diante o exposto, servimo-nos das concepções de Ponte (1994) para entender o modo de ver dos alunos que vêem como principal razão para o insucesso na disciplina de Matemática o fato desta ser extremamente difícil de compreender. E vai além: "os professores não a explica muito bem nem a torna interessante" (p. 2). Do outro lado, os alunos, que não percebem para que serve a matemática nem porque são obrigados a estudá-la. Muitos desses alunos interiorizaram nos primeiros contatos com a escola, a auto-imagem de incapacidade em relação à disciplina. E geralmente culpam-se a si próprios, aos professores e ao próprio sistema escolar.

Desmistificar essas ideias é função da escola e do professor, por isso projetos como o Matematicando são desenvolvidos em grandes escalas nas escolas brasileiras. Cujo foco é aproximar os conteúdos matemáticos à vida prática e ao dia a dia do aluno. Pois a matemática no cotidiano do aluno apresenta diversas formas de interpretação que não estão relacionadas exclusivamente com a forma matemática concreta (matemática com o uso de números, teoremas).

Em geral os profissionais dessa área tendem a pensar que sua atuação, com suas técnicas e métodos, acontece em espaço neutro, isenta de uma opção política. Para Freire (2001) "é uma ingenuidade pensar num papel abstrato, num conjunto de métodos e técnicas neutros para uma ação que se dá em realidade que também não é neutra" (p. 45).

Percebem-se nessa trajetória que a Matemática torna-se, muitas vezes, distante de seus significados e dos objetivos na Educação Básica, devido à maneira como é abordada e a ênfase dada somente à simbologia e não ao contexto, ou seja, ao fato de se apresentar como uma ciência isolada e que não está presente no cotidiano. Os PCNs do Ensino Médio salientam as competências que devem 
ser desenvolvidas com os alunos no ensino de Matemática para que eles possam interagir na sociedade, lendo, interpretando e se posicionando diante de situações reais que envolvam essa disciplina. E foi exatamente isso, que foi feito, em três grandes momentos:

Momento (1) - as maquetes: o professor tem papel fundamental na criação de um ambiente material e social encorajando a autonomia e o pensamento dos alunos; quando propomos a construção de maquetes, que retratassem a trajetória deles no percurso de suas casas até a escola, vimos nessa, uma forma de apresentar simbolicamente os conteúdos matemáticos de forma lúdica e suave, sem o peso das fórmulas e das deduções de teoremas. Como estratégias, dividimos os alunos em grupos e trabalhamos a leitura e interpretação dos conteúdos matemáticos, a partir da imagem (dos prédios, carros, ruas, formatos das casas, pessoas e etc.), depois partimos para construção das maquetes, que foram apresentadas aos alunos do ensino fundamental, primando pelo requinte nos detalhamentos dos conteúdos matemáticos ali presentes.

Momento (2): nesse segundo momento os conteúdos matemáticos tomam forma de músicas através das paródias. Elaborando estratégias de ensino envolvendo as artes (como a Música), conjectura-se que poderemos despertar o interesse dos alunos para a aprendizagem da Matemática e, possivelmente, colaborar para que surja também um interesse pela aprendizagem musical. Essa dinâmica faria com que, eles (alunos) pudessem (ler, entender e discutir) a aplicabilidade das formas e teoremas e sociáliza-los através da música. Como tínhamos na escola 16 turmas de ensino médio, achávamos que receberíamos em média, uma paródia por turma. Dai selecionaríamos as 4 melhores, que iram ao voto popular. Nos enganamos redondamente em nossa projeção. Tivemos naquela ocasião 45 (quarenta e cinco) músicas escritas e aí, tivemos que redirecionar nossas ações, criando dentro do Projeto Matematicando o Festival Canta Matemática. Conseguimos um espaço adequado para execução 
do festival, banda musical para acompanhá-los e prêmios para os três primeiros colocados. O dia do festival foi uma coisa de louco. Cada grupo com suas torcidas e faixas. Tínhamos no auditório mais de 600 alunos. A presença da TV local projetou o evento em uma dimensão ainda maior. O corpo de jurados, composto por professores de matemática de outras unidades, músicos e autoridades locais. Em resumo, o festival foi um sucesso e até hoje é lembrado pelos alunos partícipes do evento, como algo inovador.

Momento (3): No terceiro momento, fomos averiguar os possíveis resultados. Através do projeto pré-vestibular, já desenvolvido na escola, percebeu-se que esse espaço de aprofundamento teórico e de praticidade no entender e resolução de problemas matemáticos, propiciado pelo projeto matematicando, melhorou e muito, o nível de conhecimento de nossos alunos. O resultado foi um bom aproveitamento no exame do ENEM e nos vestibulares naquele ano.

\section{Segunda experiência: o nivelamento.}

O Programa de Nivelamento é um dos programas de apoio aos discentes desenvolvidos por várias instituições. A partir da oportunidade que tive, para gestar o curso de matemática em duas grandes instituições da região de Brasília, vi no nivelamento uma forma de executar de forma mais centrada no curso os ideais do Projeto Matematicando, que era propiciar ao aluno ingressante, o acesso aos conhecimentos básicos e fundamentais. Além disso, utilizamos o nivelamento para apresentar o perfil do curso de matemática e dos profissionais que esse pretendia formar. É um espaço onde os alunos têm contato matriz curricular do curso, com Projeto Político Pedagógico - PPP, e a partir dai, numa interação com os futuros professores, discutem sobre os medos e os 
possíveis dilemas que vão enfrentar no decorrer do curso e ao final criaram um "símbolo" - que nós chamamos de "mandala", que vai representar o curso, seus discentes e docentes em constante relação com a instituição e com a sociedade.

A base teórica tal para discussão foi o texto Aula: Gênese, dimensões, princípios e práticas/Ilma Passos Alencastro Veiga (org.). - Campinas, SP: Papirus, 2008. E ao final traçava-se também um perfil de sala de aula ideal.

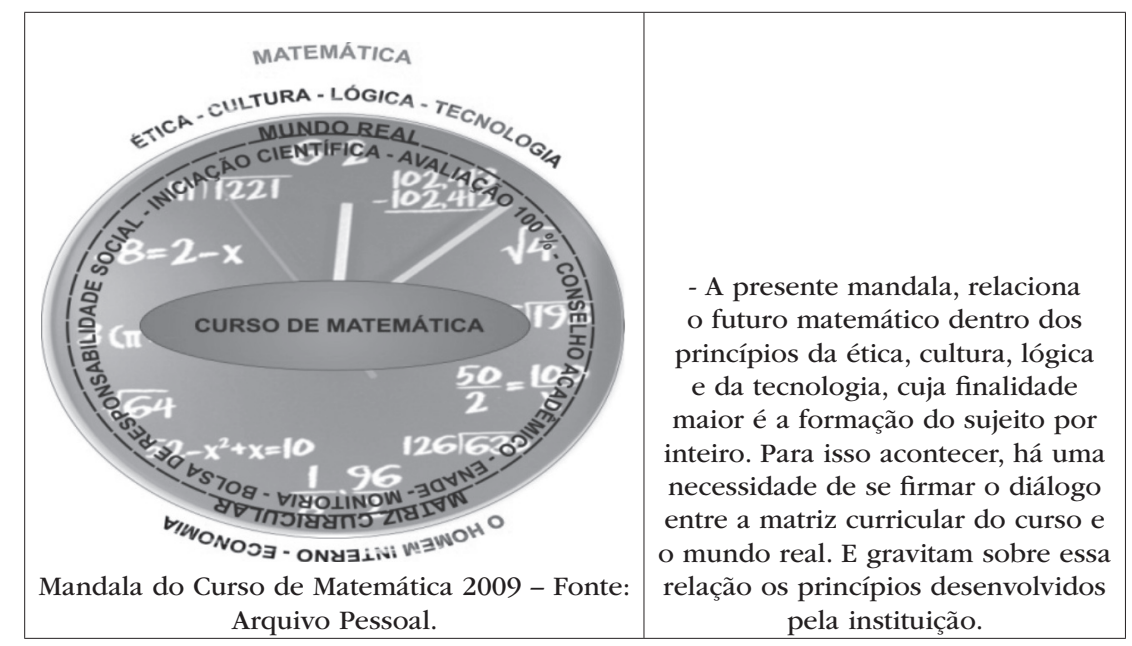

\section{A Gênese e a estrutura de sala de aula ideal, a partir das concepções de Ilma Passos}

Estruturar a sala de aula ideal para a instituição, a partir das concepções do livro em epígrafe, não é uma tarefa fácil, também garanto, que não se trata de uma tarefa impossível. O grande problema está na visão de educação que cada um construiu a partir da sua trajetória no espaço educacional, através das "imagens das experiências compartilhadas nas escolas queridas, da infância vivida, repartida, construída em espaços/tempo diversos, múltiplos, mágicos 
[...]". ${ }^{80}$ As dimensões para estruturação de uma sala de aula, devem contemplar esse espaço, como sendo um espaço de conhecimento e conhecimento se constrói na dúvida, na leitura (individual e/ou em grupo), interpretação de textos, de músicas, de filmes, etc. Por isso, a sala de aula não pode ser um espaço monótono. Tem que ser um espaço vivo.

Para Pimenta (2002) Se conhecer não reduz a informar [...], é preciso operar com as informações para adquiri-la, na direção de que a partir delas - chegar ao conhecimento -, então parece-nos que a universidade, através do professor universitário, tem um grande trabalho a realizar na sala de aula e fora dela, que é proceder à mediação entre a sociedade da informação e os alunos, no sentido de possibilitar que, pelo exercício da reflexão, adquiram a sabedoria necessária à permanente construção do humano.

Inovar a sala de aula é uma necessidade e um grande desafio para os profissionais da educação, em qualquer nível. A auto avaliação deve ser o nosso ponto de partida. Como está a minha sala de aula? De que forma ela está contribuindo para o processo de ensino e aprendizagem? Nessa caminhada, todos os atores do processo (aluno, professor e instituição) devem buscar a inovação. Estreitar as relações de diálogos deve ser o caminho utilizado pela instituição para conhecer melhor a realidade de suas salas de aulas, e fornecer o aparato teórico e metodológico a seus professores, através de um processo de formação continuada, que permitirá: a ruptura de visões e métodos simplistas; apresentar conhecimento sobre os conteúdos a serem ministrados, questionar as ideias docentes de "senso comum", condições para saber analisar criticamente o ensino tradicional, preparar

${ }^{80}$ Aula: Gênese, dimensões, princípios e práticas, Ilma Passos Alencastro Veiga (Org.) (2008). Campinas, SP: Papirus (Coleção Magistério: Formação e trabalho pedagógico). pp.15-16. 
atividades diversificadas e, sobretudo o saber avaliar a partir de diferentes métodos.

A Gênese da sala de aula deve permear:

\begin{tabular}{|c|c|}
\hline Para o aluno & Para o professor \\
\hline $\begin{array}{l}\text { A inovação no ambiente educacional } \\
\text { (sala de aula); } \\
\text { Averiguar a cultura educacional pré- } \\
\text {-existente; } \\
\text { O conhecimento das possibilidades } \\
\text { dos alunos } \\
\text { O desenvolver do (aluno) dentro } \\
\text { de um processo de autonomia e de } \\
\text { capacidade de reflexão; }\end{array}$ & $\begin{array}{l}\text { - } \quad \text { O planejar da ação didática; } \\
\text { - } \quad \text { Articulação dos objetivos propostos; } \\
\text { - Seleção organização dos conteúdos } \\
\text { curriculares; } \\
\text { - Inovação nos procedimentos } \\
\text { didáticos (metodologia) } \\
\text { Avaliação diversa. }\end{array}$ \\
\hline
\end{tabular}

O quadro acima nos remete a ideia de que a atividade docente em sala de aula envolve: sistematização, organização, ordenação, coerência, metodização, coesão, logicidade, racionalidade, entrelaçamento - certamente do conteúdo, da metodologia, da avaliação e dos seus objetivos.

\section{Terceira Experiência: A formação continuada de professores.}

A Formação Continuada de Professores de Matemática nas unidades em que trabalhamos o Projeto Matematicando baseiam-se na proposta metodológica do programa GESTAR II, oferecido pelo Governo Federal e promovido pela Universidade Federal de Goiás. É um programa importante, com características inovadoras, porque trabalha com o currículo em rede, com situação-problema ligada à realidade sócio-cultural e com a transposição para a sala de aula dos conhecimentos desenvolvidos.

Historicamente falando, e tendo os PCN's como pano de fundo percebeu que a formação continuada de professores é um dos obstáculos enfrentados pelo Brasil em relação ao ensino. Falar sobre essa temática remete-nos a uma forte tendência que atem-se apenas 
aos aspectos conceituais dos conteúdos de matemática, e quando questionados acerca dessa prática, os professores afirmaram que durante a licenciatura tiveram pouco contato com disciplinas de cunho pedagógico, problemática essa, bastante presente nos programas de formação de professores. Sobre a temática, Gonçalves (2006) atribui à situação dessa formação acadêmica que parte do uso e modelo de racionalidade técnica, onde afirma que primeiro ensinam-se os conteúdos científicos da área, posteriormente, as disciplinas pedagógicas, e por último, a prática de ensino e estágio supervisionado, colocando assim a formação pedagógica em segundo plano. E Freire, complementa que formar professores na sociedade contemporânea, requer compreender criticamente a realidade, dentro de um contexto que integre a associação à transitividade da consciência, cujo processo ocorre na experiência educativa.

Partindo das concepções de Gonçalves (2006), deparamos com Ponte (1998) que nos traz a ideia de desenvolvimento profissional, ou seja, a noção de que a formação do professor para o exercício da sua atividade profissional é um processo que envolve múltiplas etapas e que, em última análise, está sempre incompleto. Nesse contexto, Freire (2001) enfatiza, que a práxis por meio da qual o ato de conhecer e a transformação da consciência se dão, não ocorre em pura ação, ou na ação cega, mas sim, marca sua ocorrência dentro da ação e reflexão, que culmina num movimento dialético entre a reflexão crítica sobre a ação anterior.

A contribuição do Gestar, a partir do grupo de formação continuada de professores, colocou em pauta o currículo em rede que é uma forma de organizar o conhecimento em uma visão mais integrada, levando em conta que uma dada situação requer e permite explorar uma multiplicidade de conceitos e procedimentos. O que Freire (2001) chama de um "trabalhador social", que tem como tarefa primeira desvelar a realidade concomitantemente com a sua prática, permitindo que seu instrumento de trabalho - a sua disciplina - 
esteja a serviço da percepção crítica do educando (p.46). Freire, em suas entrelinhas está pontuando as situações-problema, vivenciadas pelos professores em seu cotidiano de trabalho seguindo o autor tais conceitos aparecem de forma integrada e articulada, uns dando vida e sentido aos outros. Assim, o currículo em rede permite a articulação de vários conceitos e possibilita ao aluno e ao professor conceber e representar o conhecimento como algo dinâmico, interativo e complexo e não como algo estagnado.

No foco da valorização da experiência de aluno/professor, Dewey (1979) expõe que "é natural que ao supor, as experiências de vida de seu grupo passam a fazer parte de seu repertório individual, modificando a si mesmo e a seu grupo, numa relação dialética permeada por uma intenção" (p. 3), isto é, "por várias pedagogias que, tendo consciência delas ou não, o sujeito é fruto e conseqüência" (p. 18). E Garcia (1999) complementa que a orientação prática, juntamente da acadêmica, tem sido a abordagem mais aceita para se aprender a arte, a técnica e o ofício do ensino, e, no âmbito da formação de professores, esta orientação está fundamentalmente na organização e desenvolvimento das práticas de ensino.

NOSSO ESTUDO - construção do perfil interdisciplinar. Texto construído na coletividade a partir das práticas, pelos professores em formação UNIDESC 2010.

CANÇÃO DOS HOMENS "Quando uma mulher, de certa tribo da África, sabe que está grávida, segue para a selva com outras mulheres e juntas rezam e meditam até que aparece a "canção da criança”. Quando nasce a criança, a comunidade se junta e lhe cantam a sua canção. Logo, quando a criança começa sua educação, o povo se junta e lhe cantam sua canção. Quando se torna adulto, a gente se junta novamente e canta. Quando chega o momento do seu casamento a pessoa escuta a sua canção. Finalmente, quando sua alma está para ir-se deste mundo, a 
família e amigos aproximam-se e, igual como em seu nascimento, cantam a sua canção para acompanhá-lo na "viagem". "Nesta tribo da África há outra ocasião na qual os homens cantam a canção. Se em algum momento da vida a pessoa comete um crime ou um ato social aberrante, o levam até o centro do povoado e a gente da comunidade forma um círculo ao seu redor. Então lhe cantam a sua canção". "A tribo reconhece que a correção para as condutas anti-sociais não é o castigo; é o amor e a lembrança de sua verdadeira identidade. Quando reconhecemos nossa própria canção já não temos desejos nem necessidade de prejudicar ninguém." ”Teus amigos conhecem a "tua canção" e a cantam quando a esqueces. Aqueles que te amam não podem ser enganados pelos erros que cometes ou as escuras imagens que mostras aos demais. Eles recordam tua beleza quando te sentes feio; tua totalidade quando estás quebrado; tua inocência quando te sentes culpado e teu propósito quando estás confuso. “ (Tolba Phanem) ${ }^{1}$

O texto acima é um suave convite para o entendimento da interdisciplinaridade na construção do perfil. "É importante refletir sobre o homem e conseqüentemente sobre a crise da humanidade". É o convite que a interdisciplinaridade nos faz - olhar o homem com o olhar de quem olha, mas, sobretudo, com olhar de quem é olhado. Afinal, como diz Morin (1997): o indivíduo está na sociedade que está no indivíduo. A pessoa faz parte de uma comunidade, e esta faz parte da pessoa com suas normas, linguagem e cultura que, ao mesmo tempo, é produto dessa sociedade e de sua manutenção e do status quo (p.62).

Nascer é um ato de rompimento e todo rompimento traz dor. Por isso, não é diferente o nascimento de um texto. À medida que as ideias vão fluindo, elas inquietam e no inquietar libertam o indivíduo do cativeiro que o aprisiona. No joguete das palavras, julgamo-nos às vezes possuidores de uma verdade pronta e predeterminada $\mathrm{e}$ 
queremos impô-la ou simplesmente transferi-la a qualquer custo, isso não é interdisciplinaridade. Na interdisciplinaridade a oralidade dá vida, expressa o "canto" individual de cada autor. Após o sofrimento do parto imagine a alegria da criação. Alguém seria capaz de citar a alegria de: Guimarães Rosa ao criar "O famigerado", / Aluísio de Azevedo com "O cortiço", / Machado de Assis e sua maravilhosa obra "Senhora", / Cecília Meireles com a obra "Ou isto ou aquilo"?

Fazer educação hoje é buscar o EDUC'ART (uma nova visão emundo), PRESENT'ART (uma nova leitura de educação e de mundo) e a própria ART (dar vida por meio da escrita de todo esse processo) - com bem diz Paulo Freire: é buscar a PALAVRAÇÃO, que quando colocada em prática nos leva aos status de educador Pró-ativo. O ser PRÓ-ATIVO, não pode desconectar de sua "Canção" - com bem cita o texto inicial - assim como de sua cultura, de suas raízes, de suas marcas. Marcas essas, que te identificarão aonde for.

EDUC'ART - é um convite a uma (re) educação, onde se incentive a comunicação entre as diversas áreas do conhecimento. Nesse contexto, a "Canção dos homens" poderia ser reescrita hoje sobre vários olhares, permeando vários focos e limaes. Quando uma criança nasce, o mundo recebe algo novo e ainda não pensado para a humanidade. Um enigma paira em sua volta. Poderá tornar-se um grande líder, um artista famoso, um jogador de futebol que muitas glórias trarão ao seu país, um político renomado ou simplesmente mais um coadjuvante do processo social. Independente da função que exercer, todo ser dará sua contribuição e marcará sua presença dentro do seu contexto histórico, e direta ou indiretamente contribuirá para que a humanidade seja diferente.

Talvez Cecília Meireles, tenha conseguido expressar o verdadeiro EDUC'ART quando declamou: "Eu canto, Por que o instante existe. E a minha está completa [...]".

O canto de Cecília é a canção da vida, que pode ser a canção da criança, do adolescente, do homem, da mulher, do idoso. A canção 
de um ser humano único, com suas virtudes e características. O canto é a marca individualizada de cada ser. É o ponto de partida, que oportuniza cada um reiniciar o processo. $O$ canto que embala a infância pode acalentar a vida adulta. Num mundo marcado pela violência, onde os valores se esvaíram, prevalecendo "o olho por olho, dente por dente" de Hamurabi, é fundamental que possamos entender o indivíduo como um todo. Acompanhar e participar de seu processo de identidade, de seu canto, de sua PALAVRAÇão. Entender que as nuvens não eram feitas de algodão, que 'tu' ou 'ele' não é 'aquilo', não é 'aquela', e que existem coisas mais divertidas para brincar, do que brincar de matar "índio", matar gente.

Partindo dessa construção imaginária, como será que um professor, vê seus alunos que, seja aos seis ou sete anos, seja na adolescência, postam-se diante dele para as aulas? Um professor e mais vinte ou trinta alunos, cada um com suas expectativas, suas experiências, com seu CANTO. Talvez a resposta para essa questão, seja o falar e o fazer pedagógico, ou meramente a palavra e ação do professor. "Ensinar exige compreender que a educação é uma forma de intervenção no mundo" [...] e que o mundo é feito de canto, e o canto desse mundo, dessa cidade, sou eu, é você, somos nós. Ensinar é acreditar que a igualdade é possível entre homens e mulheres, entre brancos e negros, entre jovens de classe média e ÍNDIO, DOMÉSTICA, PROSTITUTA [...]. É acreditar que a ação que move a palavra é a mesma que forma indivíduos éticos e universais e que dimensiona a pedagogia para a autonomia. E isso só será possível, quando a educação for realidade de forma INTERDISCIPLINAR.

No mundo globalizado as informações são muito rápidas. A educação é viva e a cada minuto algo novo aparece, uma informação nova e adicionada ao processo, daí a necessidade de rever, atualizar os saberes necessários à nossa prática docente. Por isso, o grande conflito da educação contemporânea é construir claras opções institucionais que possam atender o processo ensino-aprendizagem 
e que atendam aos anseios da sociedade moderna e, sobretudo, do homem moderno. Por isso, o educador do momento que não busca por meio da reflexão entender o que faz, cai no comodismo e tende a repetir os velhos erros. E nesse contexto, quem não é visto, não é lembrado. Para uma realização pessoal e profissional, o profissional da educação deve buscar estabelecer em perfil docente os seguintes Pilares:

\section{Professor inovador e reflexivo. Uma abordagem de interdisciplinaridade.}

a) Novas formas de trabalhar os conteúdos; b) Enfatizar o diálogo na relação professor x aluno; c) Potencializar-se: busca constante pela formação continuada; d) Aprender a conhecer - adquirir competências; e) Aprender a fazer - a busca pela formação profissional; f) Aprender a viver juntos - a busca de objetivos comuns e g) Aprender a ser - agir em diferentes circunstâncias.

A partir desse contexto, trabalhar os seguintes elementos:

1. Possibilidade de intervenção em sala de aula - o educador é o sujeito de sua própria prática, cabendo a ele ousar na criatividade, se instrumentalizar através de uma reflexão consciente da realidade de sua própria sala de aula.

2. Transformação - é uma conseqüência, pois a prática pedagógica se dá a partir do momento em o indivíduo conhece a gênese do conhecimento. E o processo de conhecer se constrói no (EU) e no (OUTRO).

3. Emancipação - estar livre das amarras que atrofiam o processo de ensino-aprendizagem e ousar sempre. 
4. Reconstrução - o fazer e o (re) fazer pedagógico andam juntos, pois a educação é dinâmica e requer uma constante reconstrução.

\section{Considerações Finais}

Falar de construções de saberes na relação professor e aluno não é nada fácil. Por isso, nomeamos Paulo Freire como nosso guia e orientador nesse processo. Freire (2001b) defende a tese de que não há possibilidade de se ter por um lado o professor, como o detentor único do conhecimento, como o que só ensina e, de outro lado, o educando, como aquele que está em situação de apenas aprender, ser passivo no processo ensino e aprendizagem. Defende a ideia de que o conhecimento é construído na relação dialógica, e para ele, ambos são sujeitos cognoscentes diante do objeto cognoscível que os mediam (p. 78).

Pensar nas possibilidades da formação crítica e reflexiva a partir de ensino, requer um despertar para um conhecimento emergido sobre a reflexão na ação. Que na verdade, é a capacidade de discernir entre a informação válida e inválida, correta ou incorreta, pertinente ou supérflua. Buscou-se neste texto uma rápida reflexão acerca da competência para organizar o pensamento e a ação em função da informação, recebida ou procurada, no ambiente escolar, cuja meta principal é formar, uma pessoa preparada para viver na sociedade da informação.

Partindo do ângulo filosófico do pensamento crítico, pensar no espaço escolar implica pensar na tolerância e no respeito, que tanta falta fazem no mundo contemporâneo. A filosofia e o pensamento crítico exigem uma postura de cordialidade atenta, pois temos de escutar cuidadosamente os argumentos das outras pessoas para, juntos, encontrarmos argumentos melhores e soluções mais adequadas. 
No viés freireano, foi possível entender que o educador ou a educadora crítica reflexiva, não centra a prática, nem no educando e nem no educador, nem nos conteúdos, nem nos métodos, mas a compreende nas relações de seus vários componentes, no uso coerente, por parte do educador ou da educadora dos materiais, dos métodos e das técnicas.

Diante o exposto concluímos que a escola é o lugar onde as novas competências devem ser adquiridas, reconhecidas e desenvolvidas.

\section{Referências bibliográficas}

Alarcão, I. (2003). Professores reflexivos em uma escola reflexiva. São Paulo: Editora Cortez.

Ausubel, D.P. (1982). A aprendizagem significativa: a teoria de David Ausubel. São Paulo: Moraes.

Brasil. (2000). Parecer CNE/CEB n ${ }^{\circ}$. 11/2000. Diretrizes Curriculares Nacionais para a Educação e Jovens e Adultos. Brasília: MEC.

Dewey, John. (1979). Democracia e Educação. Tradução de Godofredo Rangel e Anísio Teixeira (4. ${ }^{a}$ ed. [1. ${ }^{a}$ ed. 1916]). São Paulo: Ed. Cia. Ed. Nacional.

Freire, P. (1984). Ação Cultural para Liberdade. (7. ${ }^{\mathrm{a}}$ ed). Rio de Janeiro: Paz e Terra. Freire, P. (1985). Pedagogia do Oprimido. (14. ${ }^{a}$ ed). Rio de Janeiro: Paz e Terra.

Freire, P. (2005). Pedagogia do oprimido: Saberes necessários à prática educativa. (47. ${ }^{\mathrm{a}}$ ed.). São Paulo: Paz e Terra.

Freire, P. (2000). Pedagogia do oprimido (29. ${ }^{\mathrm{a}}$ ed. [1 ${ }^{\mathrm{a}}$ ed. 1970]). Rio de Janeiro: Paz e Terra.

Freire, P. (2001a). Ação cultural para a liberdade. $9^{\mathrm{a}}$ edição [1ª ed. 1977]. São Paulo: Paz e Terra.

Freire, P. (2001b). Extensão ou comunicação? (11. a edição [1 $1^{\mathrm{a}}$ ed. 1977]). São Paulo: Paz e Terra.

Freire, L. G. L. (2009). Auto-regulação da aprendizagem. Revista Ciências e Cognição 14, 276-286.

Garcia, C. M. (1999). Formação de Professores: para uma mudança educativa (Tradução de Isabel Narciso). Porto: Porto Editora.

Gonçalves, T. O. (2006). A Constituição do formador de professores de Matemática: a prática formadora. Belém: CEJUP ED.

Mounier, E. (1962). Manifiesto al servicio del personalismo. Madrid: Taurus.

Nóvoa, A. (2001, setembro 13). O Professor pesquisador e reflexivo. Disponível em: http://www.tvebrasil.com.br/salto/entrevistas/antonio_novoa.htm. 
Pimenta, S. G. \& Lima, M. S. L. (2004). Estágio e Docência. São Paulo: Cortez.

Pimenta, S. G. \& Anastasiou, L. das G. C.(2002). Docência no ensino superior. São Paulo: Cortez.

Ponte, J. P. (1998). Didácticas específicas e construção do conbecimento profissional. Conferência plenária realizada no IV Congresso da Sociedade Portuguesa de Ciências da Educação. Aveiro: Universidade de Aveiro.

Serrazina, L. (1999). Reflexão, conhecimento e práticas lectivas em matemática num contexto de reforma curricular no $1 .^{\circ}$ ciclo. Quadrante, 9, 139-167.

Veiga, I. P. (org.). (2008). Aula: Gênese, dimensão, princípios e práticas. Campinas, SP: Papirus (Coleção Magistério: Formação e Trabalho Pedagógico).

Zeichner, K.M. (2003). Formando professores reflexivos para a educação centrada no aluno: Possibilidades e Contradições. In: R. L. L. Barbosa (Org.), Formação de Educadores: Desafios e Perspectivas (pp. 35-55). São Paulo: Editora UNESP. 